\title{
Growth Control by Ethylene: Adjusting Phenotypes to the Environment
}

\author{
Ronald Pierik, ${ }^{1, *}$ Rashmi Sasidharan, ${ }^{1,2}$ and Laurentius A. C. J. Voesenek ${ }^{1}$ \\ ${ }^{1}$ Plant Ecophysiology, Institute of Environmental Biology, Utrecht University, Sorbonnelaan 16, 3584 CA Utrecht, The Netherlands; \\ ${ }^{2}$ Department of Biological Sciences, University of Calgary, Calgary, Alberta, T2N 1N4 Canada
}

\begin{abstract}
Plants phenotypically adjust to environmental challenges, and the gaseous plant hormone ethylene modulates many of these growth adjustments. Ethylene can be involved in environmentally induced growth inhibition as well as growth stimulation. Still, ethylene has long been considered a growth inhibitory hormone. There is, however, accumulating evidence indicating that growth promotion is a common feature in ethylene responses. This is evident in environmental challenges, such as flooding and competition, where the resulting avoidance responses can help plants avoid adversity. To show how ethylene-mediated growth enhancement can facilitate plant performance under adverse conditions, we explored a number of these exam-
\end{abstract}

ples. To escape adversity, plants can optimize growth and thereby tolerate abiotic stresses such as drought, and this response can also involve ethylene. In this article we indicate how opposing effects of ethylene on plant growth can be brought about, by discussing a unifying, biphasic ethylene response model. To understand the mechanistic basis for this multitude of ethylene-mediated growth responses, the involvement of ethylene in processes that control cell expansion is also reviewed.

Key words: Adversity; Cell wall; Environment; Ethylene; Growth; Phenotypic plasticity; Regulation.

\section{INTRODUCTION}

The role of ethylene in plant growth regulation has been a controversial research area. The best known, classic, effect of ethylene on plant growth is the inhibition of elongation growth (Abeles and others 1992). This was first described in dark-grown seedlings of pea, and later confirmed for several

Received: 30 October 2006; accepted: 2 November 2006; Online publication: 10 May 2007

*Corresponding author; e-mail: R.Pierik@uu.nl other species including Arabidopsis. Ethylene-induced inhibition of hypocotyl and root elongation, induction of radial swelling, and the formation of an exaggerated apical hook comprise the three components of what is frequently referred to as the triple response (Guzmán and Ecker 1990; Abeles and others 1992). The triple response seems to be general for many plant species. Ethylene-induced inhibition of hypocotyl elongation is restricted to dark-grown seedlings, as ethylene has been found to exert the opposite effect in the light in Arabidopsis; namely, a significant increase in hypocotyl elongation (Smalle and others 1997). Although this seems contradic- 
tory to the triple response concept, a substantial body of work has shown that ethylene can greatly stimulate internode and petiole elongation in a range of plant species from habitats that are frequently flooded. Well-known model examples are deepwater rice (Kende and others 1998) and Rumex palustris (Voesenek and others 2003), where ethylene-induced shoot elongation helps these species to outgrow the water layer when flooded (Voesenek and others 2006). It has also been known since the early 1970s that, even in roots, the elongation response to ethylene is variable (Smith and Robertson 1971). In some species, very low but elevated ethylene levels can increase, rather than inhibit, root elongation. In others, only an inhibition is seen, as reported in Visser and others (1997). A third group consists of species that seem to have fairly ethylene-unresponsive root growth (Visser and Bogemann 2006). Similarly, a closer look at dose-response relationships for ethylene-induced inhibition of hypocotyl elongation in dark-grown Arabidopsis seedlings reveals that, even there, the situation is not as clear-cut as generally thought. Slightly elevated ethylene concentrations appear to sometimes elicit a small but reproducible stimulation of hypocotyl elongation (Hua and Meyerowitz 1998; Stepanova and others 2005). On the other hand, higher concentrations seem always to inhibit hypocotyl elongation in dark-grown Arabidopsis seedlings (Binder and others 2004).

Consistent with the idea that ethylene acts as a growth inhibitor, ethylene-insensitive Arabidopsis mutants were reported to be larger than their wildtype background (Hua and others 1995). However, recent growth analyses on three species (Arabidopsis, petunia, and tobacco) revealed identical relative growth rates (RGR measured under optimal growth conditions) for ethylene-insensitive plants and their wild-type counterparts (Tholen and others 2004). However, when ethylene-insensitive plants are grown in dense stands where they have to adjust growth to the presence of wild-type neighbors, their growth is much suppressed and they reach a fivefold lower biomass than the wild type (Pierik and others 2003). Such data reinforce the understanding that ethylene is particularly important as an internal modifier that adjusts a plant's phenotype and physiology to dynamic environmental conditions (Pierik and others 2006). In addition, ethylene has been proposed to fine-tune developmental processes such as senescence of older leaves, flower abscission, and fruit ripening (Abeles and others 1992).

In this review we address ethylene as a central player in plant growth adjustments to adverse conditions (Figure 1). We do this by reviewing ethylene functioning in (1) growth adjustments that allow a plant to avoid adversity and (2) growth maintenance (tolerance) during adversity. This variety of responses includes both growth stimulatory and growth inhibitory effects of ethylene. We briefly explain our recently introduced concept of biphasic ethylene responses that unifies these apparently contradictory roles of ethylene (Pierik and others 2006). This explanation is then related to mechanistic processes that regulate cell growth, particularly at the cell wall level. Finally, we identify future challenges and propose avenues of research to enhance our understanding of the fascinating diversity of growth adjustments controlled by ethylene.

\section{Growth Responses to Consolidate Resource Capture: Regulation by ETHYLENE}

\section{Submergence Avoidance}

Many terrestrial plant species suffer severely from flooding events, such as those that occur frequently in the floodplains along rivers. Such events therefore have severe consequences for the composition and abundance of natural vegetation (Blom 1999). Floods are also detrimental to agriculture because most crops have a low submergence tolerance (Mittler 2006). However, there are species that can survive severe floods, some of them through a striking avoidance strategy (Voesenek and others 2006). Model plants in this respect are deepwater rice (Kende and others 1998) and Rumex palustris (Voesenek and others 2003), which show strong internodal (rice) and petiole (Rumex) elongation upon submergence. This allows these plants to escape the water with their youngest leaf tips and thus restore contact with the air. This solves the main problem associated with submergence: a lack of oxygen and therefore energy (Voesenek and others 2006). Underwater diffusion rates of gases are 10,000 times slower than in air, and as a consequence very little $\mathrm{CO}_{2}$ and $\mathrm{O}_{2}$ can enter the submerged plant. This limits aerobic respiration as well as energy production through photosynthesis (Mommer and others 2004) and may eventually lead to cell death.

Ethylene also cannot freely diffuse between the submerged plant and the surrounding environment. As a result, ethylene accumulates to very high levels inside submerged plants (Voesenek and others 


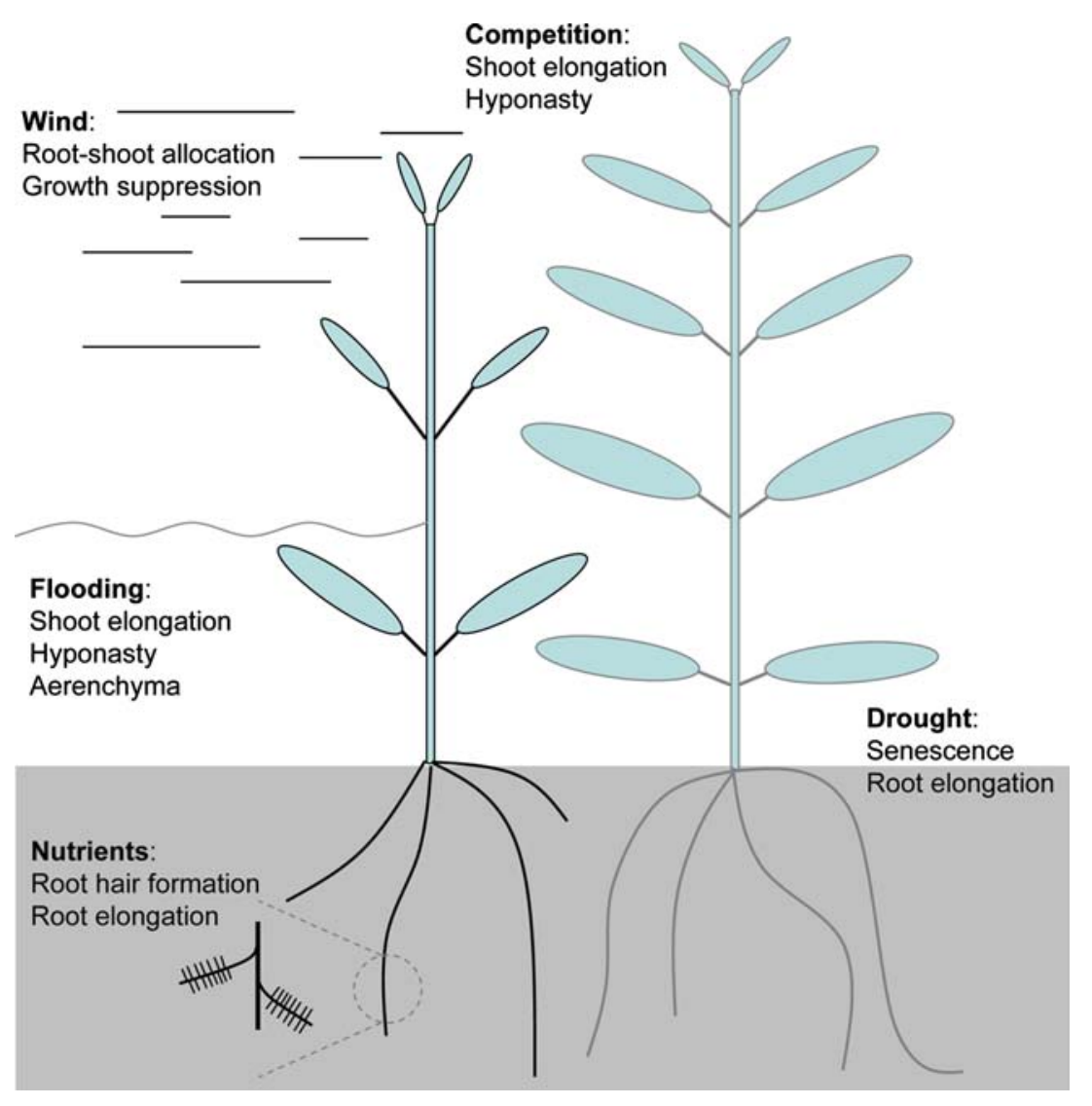

Figure 1. Ethylene modifies plant responses to various environmental challenges. These include neighbor plants, as well as several abiotic stresses, such as mechanical stress from wind, drought, flooding, and nutrient deficiency. Texts in the diagram indicate the growth adjustments to these different signals that involve ethylene.

2006). Ethylene is thought to be the primary signal to detect submerged conditions and initiate signal transduction pathways that lead to enhanced shoot elongation (Voesenek and others 2006). These pathways include several interactions between plant hormones, particularly abscisic acid (ABA) and gibberellin (GA). Upon accumulation of ethylene, endogenous ABA levels are quickly reduced. In $R$. palustris this is thought to occur through a reduced biosynthesis (indicated by submergence-induced downregulation of the RPNCED family) and enhanced breakdown (indicated by enhanced levels of phasaeic acid, an ABA breakdown product) (Benschop and others 2005). The resulting drop in ABA stimulates GA biosynthesis in $R$. palustris (Benschop and others 2006). Ethylene also enhances GA responsiveness during submergence in deepwater rice and R. palustris (Hoffmann-Benning and Kende 1992; Rijnders and others 1997). These hormones also regulate the ethylene-induced differential petiole growth to a more vertical orientation (hyponastic growth; Cox and others (2004)), a response that is also seen in Arabidopsis (Millenaar and others 2005). Hyponasty precedes petiole elongation in R. palustris and is thought to direct the elongating submerged leaves towards the water surface (Voesenek and others 2006).
Submergence-induced shoot elongation is thought to be adaptive only under relatively shallow and prolonged flooding conditions. This allows accessibility to the air and ample time for the investment to pay off (Voesenek and others 2004). However, in situations where the floods are too deep or brief to be outgrown, a "quiescence" strategy that conserves energy can be more beneficial. Recent developments in rice research have identified a genomic locus, Subl, that regulates this strategy in rice cultivars that do not exhibit a strong submergence-induced elongation (Xu and Mackill 1996). Interestingly, the importance of this locus is explained by an ethylene response factor (ERF) gene that downregulates growth factors, such as cell-wall modifying expansin proteins (Xu and others 2006). Thus, ethylene can regulate both the inhibition and the stimulation of shoot elongation. Interestingly, ethylene can also inhibit root elongation, even in species where shoot elongation is strongly promoted by ethylene. For example, although petiole elongation is increased approximately threefold by 5 ppm ethylene in R. palustris, as much as $1 \mathrm{ppm}$ of ethylene can cause a fourfold inhibition of root elongation (Visser and others 1997). Ethylene accumulation can thus be a severe drawback in several wetland species (Visser and 
Pierik 2007), but this disadvantage may well be outweighed by the benefits. These would include the formation of longitudinal air channels (aerenchyma; He and others 1992), which allow gases, notably $\mathrm{O}_{2}$, to diffuse from the emerging shoot into the root system (Colmer 2003). With this mechanism, $\mathrm{O}_{2}$ can reach the root tip meristems, which try to survive in the anaerobic soil. Ethylene also induces the formation of adventitious roots (Clark and others 1999; Steffens and others 2006), which are thick and have high occurrence of aerenchyma, thereby allowing relatively high longitudinal gas diffusion rates. In short, ethylene can induce a suite of responses that together greatly facilitate underwater aeration of the entire plant. Responses that help to avoid low oxygen conditions inside the plant thus help some terrestrial plant species to survive several months of flooding (Van Eck and others 2006; Mommer and others 2006).

\section{Shade Avoidance}

Plant growth in dense stands, such as those growing in many agricultural fields, is dominated by a strong competition for light. Upon perception of neighbor competitors, many species display a suite of responses collectively termed shade avoidance (Ballaré 1999; Franklin and Whitelam 2005). This includes upward leaf movement (hyponasty) and enhanced stem and petiole elongation, behaviors reminiscent of the submergence-avoidance responses already discussed. Shade avoidance helps plants to consolidate light capture in dense stands, and this allows them to compete better with their neighbors.

Ethylene was recently shown to be an important factor in these processes of neighbor detection and competition. Ethylene-insensitive transgenic tobacco plants, generated via insertion of the mutant etrl-1 receptor gene from Arabidopsis, were inferior competitors compared to wild-type neighbors (Pierik and others 2003). Interestingly, biomass accumulation in transgenic monocultures or in plants grown in isolation was similar to that in the wild type (Pierik and others 2004b). It was found that ethylene enhances shade avoidance responses. Ethylene-insensitive plants therefore show reduced and delayed responses to neighbors, and this causes them to be out-competed by their wild-type neighbors. Ethylene production in several species is controlled by the ratio of red:far-red (R:FR) radiation (Finlayson and others 1999; Pierik and others 2004a; Foo and others 2006; Kurepin and others 2006), which is considered the prime neighbordetection cue in dense canopies. However, ethylene may only play a minor role in the elongation re- sponses to this signal, as ethylene-insensitive tobacco did show a reasonable response to low R:FR (Pierik and others 2004c). Yet, neighbor detection involves additional signals, such as reduced photon fluence rates of blue light (Ballaré 1999; Franklin and Whitelam 2005), and mature-plant responses to this signal in tobacco are entirely ethylene-dependent (Pierik and others 2004c). Thus, ethylenemediated growth responses to light spectral cues are specific for some, but not all, light signals.

In addition to being a modulator of light-induced growth responses, ethylene might also serve as a neighbor-detection signal itself. Ethylene concentrations in the canopy atmosphere of competing tobacco plants were found to be elevated approximately threefold from 5 to $15-20 \mathrm{ppb}$ in greenhouse experiments (Pierik and others 2004c). Such concentrations were sufficiently high to induce stem elongation and hyponastic leaf growth in wild-type plants, which raises an interesting possibility. If ethylene can function as a volatile neighbor-detection cue, so could many other volatiles. Volatiles are produced during plant-herbivore interactions, and there is compelling evidence that they mediate plant-plant interactions (Baldwin and others 2006). An interesting question would be whether plantderived volatiles have the potential to induce shade avoidance responses just as they do neighbor-induced defense responses. An intriguing consequence of these possibilities is that unique species-specific volatile blends might allow plants to tune their responses to the identity of their neighbors.

\section{Foraging for Nutrients}

Plant roots typically forage for nutrients if they are in low and heterogeneous supply. This activity becomes visible as a strong induced proliferation of lateral roots in nutrient-rich patches and as limited branching in nutrient-poor areas. Such patterns are the result of reduced elongation with enhanced lateral branching in nutrient-rich patches and high primary root elongation rates during nutrient deficiency. Thus, by growing high root biomass and surface area into nutrient-rich zones, plants are thought to enhance the acquisition of nutrients when these are patchily available (Hodge 2004; de Kroon and Mommer 2006). These root-proliferation responses are thought to be of competitive and thus ecological importance when nutrients are heterogeneously supplied in vegetations with different species that have varying capacities to forage for nutrients.

As stated earlier, ethylene is generally found to inhibit root elongation. Furthermore, ethylene 
application stimulates the formation of root hairs. As a result, ethylene has been implicated in the regulation of root growth and root growth responses to different nutrient availabilities (Lynch and Brown 1997). For example, ethylene has been shown to mediate root growth adjustments upon induction by phosphorus (P) deficiency. Ethylene production is enhanced by low $\mathrm{P}$ in common bean (Phaseolus vulgaris), as is sensitivity to ethylene (Borch and others 1999). However, in maize, ethylene biosynthesis can be reduced during both phosphate and nitrogen deficiency, but in this case, ethylene responsiveness is still strongly increased (He and others 1992). Low $\mathrm{P}$ has also been suggested to enhance ethylene responsiveness in Arabidopsis roots (Ma and others 2003). More causal evidence for ethylene involvement in root foraging for nutrients came from manipulations of ethylene signaling or production. In common bean, as in many other species (Visser and Pierik 2007), ethylene inhibits root elongation under nutrient-sufficient conditions. However, it was found that, under P-deficient conditions, inhibition of ethylene biosynthesis (by applying AVG) reduced root elongation, and this was counteracted by adding exogenous ethylene. In other words, ethylene proved to be a stimulator of root growth maintenance under $\mathrm{P}$ deficiency (Borch and others 1999). Very similar results were obtained more recently on Arabidopsis root elongation. Here also ethylene stimulated growth under low $\mathrm{P}$ and inhibited growth under high P (Ma and others 2003). Growth stimulation or inhibition by ethylene thus strongly depends on the nutrient status, a conclusion reminiscent of the contrasting influence of ethylene on Arabidopsis hypocotyl length in the light and dark.

When roots encounter nutrient-poor conditions, root hair formation can be enhanced, which in turn enhances root surface area for nutrient uptake (Ma and others 2001). Root hair formation is known to be induced upon ethylene application; for example see Cao and others (1999). Consistent with this finding, the constitutive ethylene response mutant ctrl, as well as the ethylene overproducing eto 3 mutant, display ectopic root hair formation (Cao and others 1999). Native ethylene has also been implicated in root hair formation under standard conditions (Tanimoto and others 1995) and under low nutrient conditions. The ethylene-insensitive mutants ein 2 and etrl have a severely reduced root hair formation response to iron (Fe) deficiency but a perfectly normal root hair induction response to low P (Schmidt and Schikora 2001).

In conclusion, enhanced ethylene sensitivity and/ or production under nutrient-deficient conditions can augment primary root elongation, enabling plants to forage for more nutrient-rich zones. At the same time, enhanced ethylene action can, under low $\mathrm{Fe}$, but not low $\mathrm{P}$, also induce the formation of root hairs. This increases the root surface area and consequent nutrient acquisition from the rhizosphere. However, most studies on the role of ethylene in nutrient-induced root growth responses have been performed under uniform nutrient-deficient conditions. It would be interesting to know whether similar forms of regulation by ethylene govern root architecture when the nutrient supply is heterogeneous, especially because this would more likely reflect natural conditions (Jackson and Caldwell 1993).

\section{Ethylene as a Regulator of Growth Maintenance During Adversity}

\section{Thigmomorphogenesis during Mechanical Stress}

Upon exposure to mechanical stimuli, such as wind and touch, plants exhibit a suite of responses that are collectively termed thigmomorphogenesis (Jaffe and Forbes 1993; Braam 2005). These responses include reduced shoot elongation, leaf area, and dry weight accumulation. At the same time, stem diameter and root allocation typically increase upon mechanical stimulation. These phenotypic adjustments enhance a plant's resistance to mechanical failure (Jaffe and Forbes 1993; Anten and others 2005).

Ethylene has long been thought to be an important component in regulating thigmormorphogenic responses. Enhanced ethylene evolution upon mechanical stimulation is well known (Abeles and others 1992; Emery and others 1994), with the wound-induced peaks in ethylene production as perhaps the best known example (Boller and Kende 1980; Abeles and others 1992). Resulting elevated ethylene levels in Arabidopsis can stimulate the expression of TOUCH genes that are thought to be involved in signal transduction cascades from mechanical stimulation to consequent thigmomorphogenesis (Braam 2005). In addition, several articles have reported growth effects of high levels of applied ethylene that are reminiscent of thigmomorphogenesis-for example, inhibition of stem elongation (Emery and others 1994) and biomass accumulation (Anten and others 2006). Consistent with this role, elegant studies on an alpine ecotype of Stellaria longipes showed that wind-induced growth reductions could be prevented by applica- 
tion of the ethylene signaling inhibitor STS (silver thiosulfate) (Emery and others 1994). Studies on Arabidopsis, however, showed that thigmomorphogenesis does not always involve a key role for ethylene. The severely ethylene-insensitive ein2-1 and etr 1-3 mutants still show classic thigmomorphogenic responses to wind stimulation, such as reduced flower stalk elongation (Johnson and others 1998). Also, the wind-induced upregulation of TOUCH genes was unaltered in these mutants as compared to wild type. A recent study (Anten and others 2006), using the earlier mentioned ethyleneinsensitive tobacco plants, confirmed that ethylene may not be involved in mechanical stress-induced stem length stunting. However, it was also shown that the reduced biomass accumulation during mechanical stimulation does involve ethylene. Ethylene-insensitive tobacco plants showed no reduced biomass accumulation upon mechanical stress, whereas wild-type plants did. As a result, the relative allocation to roots was increased upon mechanical stimulation in wild-type. This would be an adaptive strategy in windy environments, as the roots provide anchorage and the smaller shoots reduce the wind-exposed areas (Emery and others 1994; Anten and others 2006). Because these responses require ethylene, the ability to respond to ethylene likely prevents mechanical damage in plants exposed to strong winds.

\section{Drought Stress}

Drought stress is a major abiotic constraint on plant growth that is widespread in both agricultural and natural vegetations (Bartels and Sunkar 2005). The loss of turgor during water deficit can slow cellular growth, but drought can also induce several forms of damage via, for example, protein denaturation or disruption of membrane integrity (Bray 1997). Plant cellular responses to ameliorate these drought stress symptoms are known to be regulated by abscisic acid (ABA) (Bray 1997; Bartels and Sunkar 2005). Abscisic acid production is increased under water-deficient conditions and is important for drought-induced responses (Zhu 2002). Exogenous application of $\mathrm{ABA}$ induces the expression of drought-associated genes (Zhu 2002).

Drought stress in roots leads to reduced turgor pressure, and this tends to slow cell elongation and thus root elongation. This slowing can be detrimental under water-deficient conditions, as root growth maintenance is important to explore the soil for water-rich zones. To maintain cell elongation at reduced turgor pressure, cell walls need to become more relaxed (see also the section on cell wall processes). Abscisic acid is generally associated with growth inhibition, but under water-deficient conditions it has proven essential to maintain root growth in maize. This follows from the suppression of ethylene biosynthesis by ABA (Sharp 2002). This interaction was shown when fluridone, an inhibitor of ABA biosynthesis, decreased root elongation under low water potentials and led to enhanced ethylene production. When ethylene biosynthesis was also inhibited, ABA deficiency had no effect on root elongation (Spollen and others 2000).

In addition to inhibiting root elongation, drought can also induce early leaf senescence (Young and others 2004), which reduces plant performance because of reduced carbon fixation. Ethylene is known to affect leaf senescence under normal irrigated conditions (Abeles and others 1992; Grbic and Bleecker 1995). In a maize ACC synthase knockout mutant (Zmacs6), a reduction of more than $80 \%$ in ethylene production (caused by reduced levels of the ACC synthase enzyme, which forms the ethylene precursor ACC) was associated with strong resistance of leaf function against drought. This was indicated by enhanced chlorophyll and protein levels and higher stomatal conductance under drought conditions in the Zmacs6 mutant compared to wild-type plants. This led to a much higher $\mathrm{CO}_{2}$ assimilation in the mutant under drought conditions (Young and others 2004). Similar data were obtained for wheat when ethylene biosynthesis was inhibited with AVG (Beltrano and others 1999). These data indicate that ethylene is a positive regulator of drought-induced leaf senescence and thus a negative regulator of drought tolerance. In agreement with this, exogenous ethylene can exacerbate the heat and drought-induced reduction of photosynthetic efficiency in Holm Oak (Quercus ilex), although chlorophyll levels were not affected by ethylene or drought (Munné-Bosch and others 2004). Very recently, a sunflower (Helianthus annuus) HD-Zip transcription factor (Hahb-4) was found to mediate drought and ethylene signaling. Hahb-4 expression was enhanced by drought, and Hahb-4 overexpression in Arabidopsis led to enhanced drought resistance by delaying drought-induced senescence. This is thought to occur through its transcriptional repression of genes related to ethylene biosynthesis $(A C O, S A M)$. Further reduction of ethylene-induced senescence by Hahb-4 may occur through downregulation of genes related to ethylene signaling, such as ERF2 and ERF5 (Manavella and others 2006). Interestingly, another report showed a positive contribution to drought tolerance of a tomato ethylene responsive factor (ERF), TERFl, expressed in tobacco seedlings 
(Zhang and others 2005). Thus, ERFs might have ambiguous roles in drought tolerance. They are members of the ethylene response element binding protein (EREBP) family of transcription factors, which are regulated not only by ethylene but also by various other environmental signals (Fujimoto and others 2000). This diversity of regulation might explain the variable results found for different ERFs during drought tolerance.

In conclusion, ethylene suppression appears to enhance drought resistance because it allows continuation of root growth and reduces the induction of senescence. Thus, ethylene seems to be a negative regulator of drought resistance, and plants carry mechanisms to reduce ethylene action to enhance drought resistance. The exact mechanisms that mediate interactions between ethylene and drought tolerance are not yet fully understood, however.

\section{Biphasic Ethylene Response Concept INTEGRATING GROWTH INHIBITION AND STimulation}

The examples discussed so far reveal the variable and sometimes opposing functions of ethylene signaling. For instance, ethylene's growth stimulatory role during shade and submergence avoidance seems to contradict its inhibitory role during root growth. The effects of ethylene on root growth are also ambiguous because under low $\mathrm{P}$, root elongation is stimulated rather than inhibited by ethylene. To provide a conceptual framework to understand these apparent controversies, we recently suggested a biphasic ethylene response model (Figure 2; Pierik and others 2006). In this model ethylene can have both inhibitory and stimulatory effects, depending on the concentration. This dose-response relationship is a bell curve (Figure 2) and is known in pharmacology and toxicology as a hormetic dose-response curve (Calabrese 2004). The entire doseresponse relationship in turn may be affected by environmental variables, as well as by species-specific and organ-specific differences. Environmental conditions that are known to affect ethylene responses include, for example, light quality (Pierik and others 2004a) and quantity (Smalle and others 1997), and nutrients (Borch and others 1999; Ma and others 2003). We hypothesize that various other environmental cues may also affect the exact ethylene response in any given plant species. Ethylene could thus be considered to integrate signals from various environmental cues to regulate growth adjustments. There may also have been different natural selection for ethylene-responsiveness in

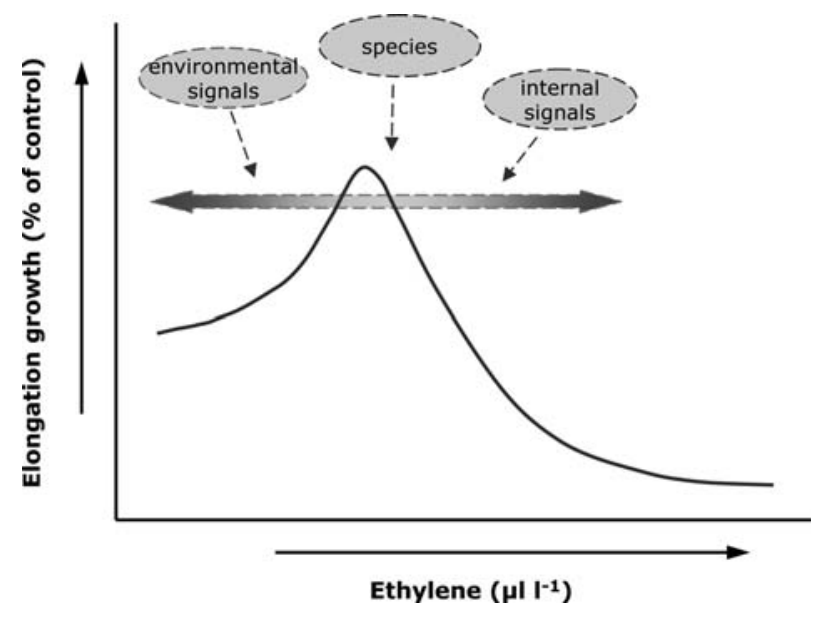

Figure 2. Hypothetical dose-growth response curve (for example, shoot elongation) to various exogenous ethylene concentrations. Note that both growth stimulation and growth inhibition may occur, depending on the concentration applied. The exact dose-response curve will differ between species and will depend on internal (for example, other plant hormones) and external (for example, light and nutrients) signals.

different environments. For example, in several frequently flooded plant species, growth stimulation occurs at very high ethylene concentrations that are realistic for submerged conditions (Voesenek and others 2006). However, such concentrations are inhibitory for most non-wetland species, which show growth stimulation only at relatively low concentrations. These low concentrations are only rarely used in experiments, especially when the ethylene precursor ACC or the ethylene-releasing compound ethephon are used, because these give ethylene levels that are relatively high and uncontrolled. As these high ethylene concentrations will represent only one end of the dose-response relationship, experimental evidence has focused mostly on growth inhibition by ethylene. In addition, it is possible that naturally low endogenous ethylene levels are often already growth-promotive. Exogenous application of relatively high ethylene doses will then frequently raise ethylene levels to growthinhibitory concentrations. We argue that growth stimulation by ethylene may be more common than previously thought.

\section{Mechanisms of Ethylene-Induced Cell Growth Regulation}

Ethylene can affect growth at the cellular level, via regulation of processes that control the ability of the 
cell to expand. Plant cell walls are rigid structures, providing mechanical support to the cells they encase. Yet in an apparent contradiction, these walls have to extend to allow cell expansion and growth. Cell wall extensibility is considered a major regulatory point in growth. Plant cell walls are composed of cellulose microfibrils embedded in a matrix of complex polysaccharides. Broadly speaking these pectins and hemicelluloses act via a multitude of noncovalent interactions with each other and with cellulose fibers, to form a network that holds the cell wall together.

\section{Cell Wall Loosening}

Cell wall extensibility depends on the modification of the above-mentioned molecular framework, a process that has been termed wall loosening (Cosgrove 2005). This in turn results from the action of a host of cell wall proteins that act on wall structural polymers, "loosening" the framework and thus allowing extension. Agents such as hormones that affect extensibility and consequent growth do so in part via their influence on the activities and expression levels of these modifying agents. A number of wall-loosening agents have now been identified (Darley and others 2001; Cosgrove 2005), and most of them act primarily on the cellulose:hemicellulose network. Among these, members of the expansin, xyloglucan endotransglycosylase/hydrolase (XTH), and endo- $\beta 1,4-\mathrm{D}-$ glucanase family are ethylene regulated (Figure 3).

Expansins are a family of cell wall proteins that mediate the acid-induced extension seen in isolated plant walls. Expansins are thought to act via disruption of the hemicellulose-cellulose noncovalent interactions, which allows slippage of the loadbearing polymers and thus, expansion (Cosgrove 2005). In most plant species expansins comprise a multigene family, where members show differential regulation by various factors (Cosgrove and others 2002). Numerous studies have now provided evidence for ethylene-mediated regulation of expansins. For example, ethylene-regulated expansins are involved in fruit ripening (Rose and others 1997; Hiwasa and others 2003) and abscission (Belfield and others 2005). As mentioned earlier, in semi-aquatic plants, such as deepwater rice and $R$. palustris, the flooding responses are initiated by ethylene (Kende and others 1998; Voesenek and others 2003).

In R. palustris, ethylene affects cell wall loosening during flooding-induced petiole elongation in a two-pronged process. Fast, apoplastic acidification resulting from $\mathrm{H}^{+}$extrusion probably sets the

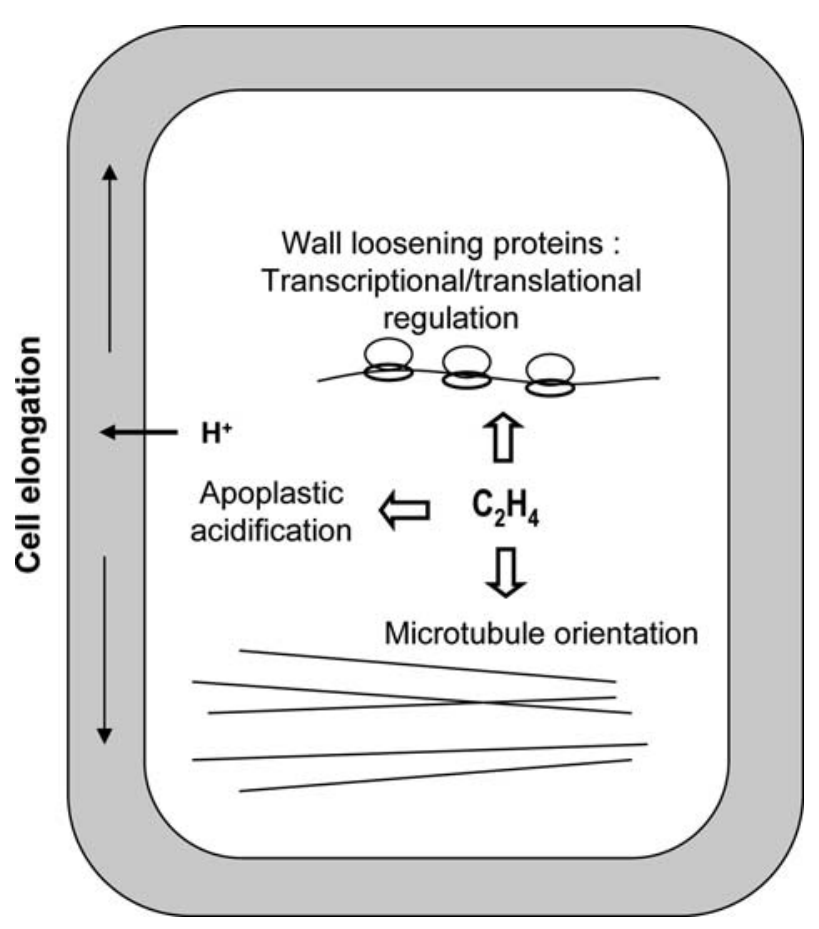

Figure 3. Ethylene regulates various processes to modify cell elongation. These include cell wall loosening through regulation of mRNA and protein levels of cell wall loosening proteins, such as expansins. Furthermore, ethylene can enhance proton extrusion into the apoplast, which is thought to enhance the activity of cell wall modifying proteins. The directionality of cell expansion is related to microtubule orientation, which is also ethyleneregulated.

optimal acidic environment for the action of cell wall loosening proteins. Transcript levels of $R p E X$ $P A 1$ increase, followed by increased expansin protein levels. This combination of events is thought to enhance cell expansion and thus petiole elongation (Vreeburg and others 2005). In deepwater rice, expansins also show distinct expression patterns that correlate with the internodal elongation seen in response to flooding and GA (Cho and Kende 1997). In rice, it is now known that ethylene- and GAmediated changes in gene expression are controlled by the Subl locus, containing the ERF-like gene Subla, which confers submergence tolerance $\mathrm{Xu}$ and others 2006). The cultivar $\mathrm{M} 2 \mathrm{O} 2$ shows increased shoot elongation after $14 \mathrm{~d}$ of flooding. In contrast, when the Subl locus from a non-elongating cultivar (FR13-A) was introgressed into M2O2, the resulting $\mathrm{M} 2 \mathrm{O} 2$ (Subl) near-isogenic line had lost the elongation response to flooding. In response to ethylene, M2O2 plants showed increased expression of expansin genes. In $\mathrm{M} 2 \mathrm{O} 2$ (Subl), where ethylene caused an induction of SublA 
transcripts, expansin gene expression was either unchanged or even downregulated. This suggests that ethylene can cause both upregulation and downregulation of wall-loosening genes in response to a similar signal (flooding) (Fukao and others 2006).

The ethylene-mediated submergence response is conserved in certain ferns as well. In response to submergence or ethylene treatment, transcript levels of an RdEXPAl mRNA were upregulated in the elongating rachises of Regnellidium diphyllum (Kim and others 2000). Also, in cotton (Gossypium hirsutum) plants, fiber cell elongation was found to be controlled by ethylene. Elongating fiber cells produce large amounts of ethylene, and application of exogenous ethylene stimulates elongation. This correlates with the upregulation of a number of genes, including two expansins ChEXPAl and ChEXPA2 (Shi and others 2006). Expansins are thus central players in many ethylene-mediated elongation growth responses, but cell wall loosening is brought about by more enzymes.

Xyloglucan endotransglucosylase/hydrolases (XTHs) are a family of cell wall enzymes that can modify their substrate hemicellulose (xyloglucan) via hydrolysis or transglucosylation. They are also involved in diverse processes such as expansion, abscission, and fruit ripening (Rose and others 2002). For example, root growth maintenance under water deficit in maize requires enhanced cell wall loosening to allow cell expansion under reduced turgor pressure. This wall loosening in water-stressed maize roots involves both expansins (Wu and others 2001) and XTH (Wu and others 1994). Although XTH upregulation was dependent on ABA accumulation, it was not known whether ethylene might be involved. However in hot pepper, an ethylene-inducible XTH was identified that increased drought and salt tolerance in transgenic Arabidopsis plants (Cho and others 2006). In maize, ethylene-induced aerenchyma formation through cell lysis (an adaptive response to flooding), is also associated with the upregulation of an XTH (wus1005) (Saab and Sachs 1996).

The third major family of wall-modifying enzymes are the endo-1,4- $\beta$-D-glucanases (EGases). These cause the endo-hydrolysis of $\beta 1,4$ linkages of cell wall glucans, which thereby alter wall composition. EGases have been mostly associated with growing tissues and organs, but they also have a function in fruit ripening and abscission (Darley and others 2001). In tomato, an EGase Cel4 transcript was found in rapidly expanding tissues such as young pistils, etiolated hypocotyls, and young leaves. Application of ethylene or high concentra- tions of 2,4 D (a synthetic auxin) to tomato seedlings, caused a doubling of the concentration of $\mathrm{Cel} 4$ mRNA. Because high concentrations of 2,4 D cause an increase in ethylene production, it was concluded that the transcript abundance observed was either a direct or indirect consequence of ethylene action (Brummell and others 1997).

\section{Microtubule Orientation}

The action of the above-mentioned enzyme groups on the cell wall allows it to extend. However, for cell elongation this extension needs to be unidirectional or anisotropic. One of the factors implicated in the control of growth anisotropy is the cytoskeletal microtubule network. The elongation status of a cell and the orientation of microtubules (MT) seem to follow a simple, though not absolute, rule. With respect to the long axis of growth, the orientation of MTs is transverse in an elongating cell and longitudinal in a non elongating cell (Fischer and Schopfer 1997). The exact mechanism of how this MT reorientation leads to the control of growth anisotropy has been controversial. The observed coalignment of MTs with cellulose microfibrils led to the hypothesis that MTs control cell expansion by influencing the deposition of cellulose in the wall (Baskin 2001). Although this theory had been discounted by studies that uncoupled this relationship (Baskin 2001; Himmelspach and others 2003; Sugimoto and others 2003), it has been revived by a recent study demonstrating the functional association of cellulose synthase with MTs (Paredez and others 2006).

The effects of ethylene on MTs has been studied in the pea (Pisum sativum) stem and epicotyl, and the mung bean (Vigna radiata) hypocotyl (Lang and others 1982; Roberts and others 1985). In each case, high concentrations of ethylene caused MTs to switch to a predominantly longitudinal orientation concomitant with an inhibition of elongation. This correlation, however, may be restricted to ethylene-induced growth inhibition. Hypocotyl elongation of light-grown Arabidopsis seedlings was stimulated by ethylene, for which elongating cells still showed MT orientations other than the expected transverse order. Thus growth and MT patterning may not always be unambiguously related (Le and others 2005).

In conclusion, regulation of cell elongation by ethylene might be brought about by a combination of factors that affect cell wall mechanics. There clearly are multiple regulation points, including translational and transcriptional control of cell wall enzymes and tubulin and control of 
MT dynamics (Figure 3), which in turn might affect deposition of cell wall polysaccharides and secretory enzymes.

\section{Conclusions and Perspectives}

Ethylene is an important modulator of diverse growth responses to a wide variety of environmental cues. It can be an inhibitor as well as a stimulator of growth, depending on the environmental challenges and species-specific characteristics, including balances with other growth regulating hormones. Because plants under natural conditions are likely to encounter multiple challenges, a proper integration of these signals is required to reach a coordinated and appropriate output. Ethylene might be at the heart of these integrational processes as it is regulated by a wide variety of environmental signals and is functionally important for growth responses to these cues. Ethylene signaling is therefore a likely candidate for signal integration. Signal integration also implies a role for ethylene in determining hierarchies between responses to multiple environmental challenges. An interesting recent example is the relationship between shade-avoidance responses to consolidate light capture and defense responses against herbivory in wild tobacco (Nicotiana longiflora). A low R:FR light ratio was found to enhance stem elongation, and also to strongly suppress the expression of defense-related genes and herbivoreinduced phenolic compounds. This led to enhanced performance of the specialist herbivore Manduca sexta on shade-avoiding plants as compared to controls (Izaguirre and others 2006). Together, these various points of evidence suggest that low R:FRinduced ethylene production stimulates shade avoidance (Pierik and others 2003) but suppresses at least some defense responses in tobacco (Winz and Baldwin 2001). This would thus mean that consolidation of light acquisition dominates and even goes at the expense of defense against herbivory.

It will be an exciting future challenge to elucidate the regulatory routes through which ethylene can have these diverse and sometimes opposite effects on growth. Much will depend on crosstalk with other hormones, such as ABA, GA, and auxin. Their mutual output contributing to cell wall processes will at least partially define the cellular growth responses. The ethylene-responsive EREBP family of transcription factors is a likely signal-transduction step for integration of multiple signals and for diversification of outputs. Members of this large family of proteins can be regulated by ethylene, as well as by many other signals (Fujimoto and others 2000). Furthermore, different members of this family can have different functions. For example, the SublA ERF-like gene in rice is induced by ethylene and appears to suppress elongation growth, at least in part by suppressing expansins. In contrast, although SublC is also regulated by ethylene (and also by GA), it has been proposed to stimulate elongation growth (Fukao and others 2006). It will be interesting to find out whether a growth stimulatory role of SUBIC occurs through an opposite regulation of the same expansins as those downregulated by SUBlA, or alternatively through other cell wall modifying processes. Similar approaches have the potential to shed light on many aspects of ethylene-mediated growth adjustments and may ultimately clarify how this hormone can have such a profound diversity of effects on plant growth.

\section{ACKNOWLEDGMENTS}

We acknowledge funding by the Netherlands Organisation for Scientific Research (PIONIER grant nr. 80074470 to L.A.C.J.V., and VENI grant nr. 86306001 to R.P.) and the National Science and Engineering Research Council of Canada (R.S. through a Discovery Grant to Dr. C. C. Chinnappa, University of Calgary). We thank Ton Peeters for helpful comments on a draft of this manuscript.

\section{REFERENCES}

Abeles FB, Morgan PW, Saltveit ME. 1992. Ethylene in Plant Biology. San Diego, CA, USA: Academic Press, pp 1-398.

Anten NPR, Casado-Garcia R, Nagashima H. 2005. Effects of mechanical stress and plant density on mechanical characteristics, growth, and lifetime reproduction of tobacco plants. Am Nat 166:650-660.

Anten NPR, Casado-Garcia R, Pierik R, Pons TL. 2006. Ethylene sensitivity affects changes in growth patterns, but not stem properties, in response to mechanical stress in tobacco. Physiol Plant 128:274-282.

Baldwin IT, Halitschke R, Paschold A, von Dahl CC, Preston CA. 2006. Volatile signaling in plant-plant interactions: "talking trees" in the genomics era. Science 311:812-815.

Ballaré CL. 1999. Keeping up with the neighbours: phytochrome sensing and other signalling mechanisms. Trends Plant Sci 4:97-102.

Bartels D, Sunkar R. 2005. Drought and salt tolerance in plants. Crit Rev Plant Sci 24:23-58.

Baskin TI. 2001. On the alignment of cellulose microfibrils by cortical microtubules: a review and a model. Protoplasma 215:150-171.

Belfield EJ, Ruperti B, Roberts JA, Queen-Mason S. 2005. Changes in expansin activity and gene expression during ethylene-promoted leaflet abscission in Sambucus nigra. J Exp Bot 56:817-823. 
Beltrano J, Ronco MG, Montaldi ER. 1999. Drought stress syndrome in wheat is provoked by ethylene evolution imbalance and reversed by rewatering, aminoethoxyvinylglycine, or sodium benzoate. J Plant Growth Regul 18:59-64.

Benschop JJ, Bou J, Peeters AJM, Wagemaker N, Guhl K, and others 2006. Long-term submergence-induced elongation in Rumex palustris requires abscisic acid-dependent biosynthesis of gibberellin. Plant Physiol 141:1644-1652.

Benschop JJ, Jackson MB, Guhl K, Vreeburg RAM, Croker SJ, and others 2005. Contrasting interactions between ethylene and abscisic acid in Rumex species differing in submergence tolerance. Plant J 44:756-768.

Binder BM, O'Malley OC, Wang W, Moore JM, Parks BM, and others 2004. Arabidopsis seedling growth response and recovery to ethylene. A kinetic analysis. Plant Physiol 136:29132920.

Blom CWPM. 1999. Adaptations to flooding stress: from plant community to molecule. Plant Biol 1:261-273.

Boller T, Kende H. 1980. Regulation of wound ethylene synthesis in plants. Nature 286:259-260.

Borch K, Bouma TJ, Lynch JP, Brown KM. 1999. Ethylene: a regulator of root architectural responses to soil phosphorus availability. Plant Cell Environ 22:425-431.

Braam J. 2005. In touch: plant responses to mechanical stimuli. New Phytol 165:373-389.

Bray EA. 1997. Plant responses to water deficit. Trends Plant Sci $2: 48-54$.

Brummell DA, Bird CR, Schuch W, Bennett AB. 1997. An endo1,4-beta-glucanase expressed at high levels in rapidly expanding tissues. Plant Mol Biol 33:87-95.

Calabrese EJ. 2004. Hormesis: from marginalization to mainstream: a case for hormesis as the default dose-response model in risk assessment. Toxicol Appl Pharmacol 197:125-136.

Cao XF, Linstead P, Berger F, Kieber J, Dolan L. 1999. Differential ethylene sensitivity of epidermal cells is involved in the establishment of cell pattern in the Arabidopsis root. Physiol Plant 106:311-317.

Cho HT, Kende H. 1997. Expression of expansin genes is correlated with growth in deepwater rice. Plant Cell 9:16611671.

Cho SK, Kim JE, Park JA, Eom TJ, Kim WT. 2006. Constitutive expression of abiotic stress-inducible hot pepper CaXTH3, which encodes a xyloglucan endotransglucosylase/hydrolase homolog, improves drought and salt tolerance in transgenic Arabidopsis plants. FEBS Lett 580:3136-3144.

Clark DG, Gubrium EK, Barrett JE, Nell TA, Klee HJ. 1999. Root formation in ethylene-insensitive plants. Plant Physiol 121:5359.

Colmer TD. 2003. Long-distance transport of gases in plants: a perspective on internal aeration and radial oxygen loss from roots. Plant Cell Environ 26:17-36.

Cosgrove DJ. 2005. Growth of the plant cell wall. Nature Cell Biol 6:850-861.

Cosgrove DJ, Li LC, Cho HT, Hoffmann-Benning S, Moore RC, and others 2002. The growing world of expansins. Plant Cell Physiol 43:1436-1444.

Cox MCH, Benschop JJ, Vreeburg RAM, Wagemaker CAM, Moritz T, and others 2004. The roles of ethylene, auxin, abscisic acid, and gibberellin in the hyponastic growth of submerged Rumex palustris petioles. Plant Physiol 136:29482960.

Darley CP, Forrester AM, Queen-Mason SJ. 2001. The molecular basis of plant cell wall extension. Plant Mol Biol 47:179-195.

de Kroon H, Mommer L. 2006. Root foraging theory put to the test. Trends Ecol Evol 21:113-116.
Emery RJN, Reid DM, Chinnappa CC. 1994. Phenotypic plasticity of stem elongation in two ecotypes of Stellaria longipes: the role of ethylene and response to wind. Plant Cell Environ 17:691700

Finlayson SA, Jung I-J, Mullet JE, Morgan PW. 1999. The mechanism of rhythmic ethylene production in sorghum. The role of phytochrome B and simulated shading. Plant Physiol 119:1083-1089.

Fischer K, Schopfer P. 1997. Interaction of auxin, light, and mechanical stress in orienting microtubules in relation to tropic curvature in the epidermis of maize coleoptiles. Protoplasma 196:108-116.

Foo E, Ross JJ, Davies NW, Reid JB, Weller JL. 2006. A role for ethylene in the phytochrome-mediated control of vegetative development. Plant J 46:911-921.

Franklin KA, Whitelam GC. 2005. Phytochromes and shadeavoidance responses in plants. Ann Bot 96:169-175.

Fujimoto SY, Ohta M, Usui A, Shinshi H, Ohme-Takagi M. 2000. Arabidopsis ethylene-responsive element binding factors act as transcriptional activators or repressors of GCC box-mediated gene expression. Plant Cell 12:393-404.

Fukao T, Xu KN, Ronald PC, Bailey-Serres J. 2006. A variable cluster of ethylene response factor-like genes regulates metabolic and developmental acclimation responses to submergence in rice. Plant Cell 18:2021-2034.

Grbic V, Bleecker AB. 1995. Ethylene regulates the timing of leaf senescence in Arabidopsis. Plant J 8:595-602.

Guzmán P, Ecker JR. 1990. Exploiting the triple response of Arabidopsis to identify ethylene-related mutants. Plant Cell 2:513-523.

He C-J, Morgan PW, Drew MC. 1992. Enhanced sensitivity to ethylene in nitrogen- or phosphate-starved roots of Zea mays $\mathrm{L}$. during aerenchyma formation. Plant Physiol 98: 137-142.

Himmelspach R, Williamson RE, Wasteneys GO. 2003. Cellulose microfibril alignment recovers from DCB-induced disruption despite microtubule disorganization. Plant J 36:565-575.

Hiwasa K, Rose JKC, Nakano R, Inaba A, Kubo Y. 2003. Differential expression of seven $\alpha$-expansin genes during growth and ripening of pear fruit. Physiol Plant 117:564-572.

Hodge A. 2004. The plastic plant: root responses to heterogeneous supplies of nutrients. New Phytol 162:9-24.

Hoffmann-Benning S, Kende H. 1992. On the role of abscisic acid and gibberellin in the regulation of growth in rice. Plant Physiol 99:1156-1161.

Hua J, Chang C, Sun Q, Meyerowitz EM. 1995. Ethylene insensitivity conferred by Arabidopsis ERS gene. Science 269:1712-1714

Hua J, Meyerowitz EM. 1998. Ethylene responses are negatively regulated by a receptor gene family in Arabidopsis thaliana. Cell 94:261-271.

Izaguirre MM, Mazza CA, Biondini M, Baldwin IT, Ballare CL. 2006. Remote sensing of future competitors: impacts on plant defenses. Proc Natl Acad Sci USA 103:7170-7174.

Jackson RB, Caldwell MM. 1993. Geostatistical patterns of soil heterogeneity around individual perennial plants. J Ecol 81:683-692.

Jaffe MJ, Forbes S. 1993. Thigmomorphogenesis-the effect of mechanical perturbation on plants. Plant Growth Regul $12: 313-324$

Johnson KA, Sistrunk ML, Polisenky DH, Braam J. 1998. Arabidopsis thaliana responses to mechanical stimulation do not require ETR1 or EIN2. Plant Physiol 116:643-649.

Kende H, Van der Knaap E, Cho H-T. 1998. Deepwater rice: a model plant to study stem elongation. Plant Physiol 118:11051110 . 
Kim JH, Cho H-T, Kende H. 2000. A-expansins in the semiaquatic ferns Marsilea quadrifolia and Regnellidium diphyllum: evolutionary aspects and physiological role in rachis elongation. Planta 212:85-92.

Kurepin LV, Walton LJ, Reid DM, Pharis RP, Chinnappa CC. 2006. Growth and ethylene evolution by shade and sun ecotypes of Stellaria longipes in response to varied light quality and irradiance. Plant Cell Environ 29:647-652.

Lang JM, Eisinger WR, Green PB. 1982. Effects of ethylene on the orientation of microtubules and cellulose microfibrils of pea epicotyl cells with polylamellata cell walls. Protoplasma 110:514.

Le J, Vandenbussche F, De Cnodder T, Van der Straeten D, Verbelen JP. 2005. Cell elongation and microtubule behavior in the Arabidopsis hypocotyl: responses to ethylene and auxin. J Plant Growth Regul 24:166-178.

Lynch J, Brown KM. 1997. Ethylene and plant responses to nutritional stress. Physiol Plant 100:613-619.

Ma Z, Baskin TI, Brown KM, Lynch J. 2003. Regulation of root elongation under phosphorus stress involves changes in ethylene responsiveness. Plant Physiol 131:1381-1390.

Ma Z, Walk TC, Marcus A, Lynch JP. 2001. Morphological synergism in root hair length, density, initiation and geometry for phosphorus acquisition in Arabidopsis thaliana: a modeling approach. Plant Soil 236:221-235.

Manavella PA, Arce AL, Dezar CA, Bitton F, Renou J-P, and others 2006. Cross-talk between ethylene and drought signalling pathways is mediated by the sunflower Hahb-4 transcription factor. Plant J 48:125-137.

Millenaar FF, Cox MCH, van Berkel YEM, Welschen RAM, Pierik $\mathrm{R}$, and others 2005. Ethylene-induced differential growth of petioles in Arabidopsis. Analyzing natural variation, response kinetics, and regulation. Plant Physiol 137:998-1008.

Mittler R. 2006. Abiotic stress, the field environment and stress combination. Trends Plant Sci 11:15-19.

Mommer L, Lenssen JPM, Huber H, Visser EJW, de Kroon H. 2006. Ecophysiological determinants of plant performance under flooding: a comparative study of seven plant families. $\mathrm{J}$ Ecol 94:1117-1129.

Mommer L, Pedersen O, Visser EJW. 2004. Acclimation of a terrestrial plant to submergence facilitates gas exchange under water. Plant Cell Environ 27:1281-1287.

Munné-Bosch S, Penuelas J, Ansenio D, Llusia J. 2004. Airborne ethylene may alter antioxidant protection and reduce tolerance of Holm oak to heat and drought stress. Plant Physiol 136:2937-2947.

Paredez AR, Somerville CR, Ehrhardt DW. 2006. Visualization of cellulose synthase demonstrates functional association with microtubules. Science 312:1491-1495.

Pierik R, Cuppens MLC, Voesenek LACJ, Visser EJW. 2004a. Interactions between ethylene and gibberellins in phytochrome-mediated shade avoidance responses in tobacco. Plant Physiol 136:2928-2936.

Pierik R, Tholen D, Poorter H, Visser EJW, Voesenek LACJ. 2006. The Janus face of ethylene: growth inhibition and stimulation. Trends Plant Sci 11:176-183.

Pierik R, Visser EJW, de Kroon H, Voesenek LACJ. 2003. Ethylene is required in tobacco to successfully compete with proximate neighbours. Plant Cell Environ 26:1229-1234.

Pierik R, Voesenek LACJ, de Kroon H, Visser EJW. 2004b. Density-induced plant size reduction and size inequalities in ethylene-sensing and ethylene-insensitive tobacco. Plant Biol 6:201-205.

Pierik R, Whitelam GC, Voesenek LACJ, de Kroon H, Visser EJW. 2004c. Canopy studies on ethylene-insensitive tobacco identify ethylene as a novel element in blue light and plant-plant signalling. Plant J 38:310-319.

Rijnders JHGM, Yang YY, Kamiya Y, Takahashi N, Barendse GWM, and others 1997. Ethylene enhances gibberellin levels and petiole sensitivity in flooding-tolerant Rumex palustris but not in flooding-intolerant $R$. acetosa. Planta 203:20-25.

Roberts IN, Lloyd CW, Roberts K. 1985. Ethylene-induced microtubule reoreintations: mediation by helical arrays. Planta 164:439-447.

Rose JKC, Braam J, Fry SC, Nishitani K. 2002. The XTH family of enzymes involved in xyloglucan endotransglucosylation and endohydrolysis: current perspectives and a new unifying nomenclature. Plant Cell Physiol 43:1421-1435.

Rose JKC, Lee HH, Bennett AB. 1997. Expression of a divergent expansin gene is fruit-specific and ripening-regulated. Proc Natl Acad Sci USA 94:5955-5960.

Saab IN, Sachs MM. 1996. A flooding-induced xyloglucan endo-transglycosylase homolog in maize is responsive to ethylene and associated with aerenchyma. Plant Physiol 112:385-391.

Schmidt W, Schikora A. 2001. Different pathways are involved in phosphate and iron stress-induced alterations of root epidermal cell development. Plant Physiol 125:2078-2084.

Sharp RE. 2002. Interaction with ethylene: changing views on the role of abscisic acid in root and shoot growth responses to water stress. Plant Cell Environ 25:211-222.

Shi YH, Zhu SW, Mao XZ, Feng JX, Qin YM, and others 2006. Transcriptome profiling, molecular biological, and physiological studies reveal a major role for ethylene in cotton fiber cell elongation. Plant Cell 18:651-664.

Smalle J, Haegman M, Kurepa J, Van Montagu M, Van der Straeten D. 1997. Ethylene can stimulate Arabidopsis hypocotyl elongation in the light. Proc Natl Acad Sci USA 94:27562761.

Smith KA, Robertson PD. 1971. Effect of ethylene on root extension of cereals. Nature 234:148-149.

Spollen WG, LeNoble ME, Samuels TD, Bernstein N, Sharp RE. 2000. Abscisic acid accumulation maintains maize primary root elongation at low water potentials by restricting ethylene production. Plant Physiol 122:967-976.

Steffens B, Wang JX, Sauter M. 2006. Interactions between ethylene, gibberellin and abscisic acid regulate emergence and growth rate of adventitious roots in deepwater rice. Planta 223:604-612.

Stepanova AN, Hoyt JM, Hamilton AA, Alonso JM. 2005. A link between ethylene and auxin uncovered by the characterization of two root-specific ethylene-insensitive mutants in Arabidopsis. Plant Cell 17:2230-2242.

Sugimoto K, Himmelspach R, Williamson RE, Wasteneys GO. 2003. Mutation or drug-dependent microtubule disruption causes radial swelling without altering parallel cellulose microfibril deposition in Arabidopsis root cells. Plant Cell 15:1414-1429.

Tanimoto M, Roberts K, Dolan L. 1995. Ethylene is a positive regulator of root hair development in Arabidopsis thaliana. Plant J 8:943-948.

Tholen DJH, Voesenek LACJ, Poorter H. 2004. Ethylene insensitivity does not increase leaf area or relative growth rate in Arabidopsis, Nicotiana tabacum, and Petunia x hybrida. Plant Physiol 134:1803-1812.

Van Eck WHJM, Lenssen JPM, Van de Steeg HM, Blom CWPM, de Kroon H. 2006. Seasonal dependent effects of flooding on plant species survival and zonation: a comparative study of 10 terrestrial grassland species. Hydrobiologia 565:59-69. 
Visser EJW, Bogemann GM. 2006. Aerenchyma formation in the wetland plant Juncus effusus is independent of ethylene. New Phytol 171:305-314.

Visser EJW, Nabben RHM, Blom CWPM, Voesenek LACJ. 1997. Elongation by primary lateral roots and adventitious roots during conditions of hypoxia and high ethylene concentrations. Plant Cell Environ 20:647-653.

Visser EJW, Pierik R. 2007. Inhibition of root elongation by ethylene in wetland and non-wetland plant species and the impact of longitudinal ventilation. Plant Cell Environ 30:3138.

Voesenek LACJ, Benschop JJ, Bou J, Cox MCH, Groeneveld HW, and others 2003. Interactions between plant hormones regulate submergence-induced shoot elongation in the floodingtolerant dicot Rumex palustris. Ann Bot 91:205-211.

Voesenek LACJ, Colmer TD, Pierik R, Millenaar FF, Peeters AJM. 2006. How plants cope with complete submergence. New Phytol 170:213-226.

Voesenek LACJ, Rijnders JHGM, Peeters AJM, Van de Steeg HM, de Kroon H. 2004. Plant hormones regulate fast shoot elongation under water: from genes to community. Ecology 85:1627.

Vreeburg RAM, Benschop JJ, Peeters AJM, Colmer TD, Ammerlaan A, and others 2005. Ethylene regulates fast apoplastic acidification and expansin A transcription during submergence-induced petiole elongation in Rumex palustris. Plant J 43:597-610.
Winz RA, Baldwin IT. 2001. Molecular interactions between the specialist herbivore Manduca sexta (Lepidoptera, Sphingidae) and its natural host Nicotiana attenuata. IV. Insect-induced ethylene reduces jasmonate-induced nicotine accumulation by regulating putrescine $\mathrm{N}$-methyltransferase transcripts. Plant Physiol 125:2189-2202.

Wu YJ, Spollen WG, Sharp RE, Hetherington PR, Fry SC. 1994. Root-growth maintenance at low water potentials-increased activity of xyloglucan endotransglycosylase and its possible regulation by abscisic-acid. Plant Physiol 106:607-615.

Wu YJ, Thorne ET, Sharp RE, Cosgrove DJ. 2001. Modification of expansin transcript levels in the maize primary root at low water potentials. Plant Physiol 126:1471-1479.

Xu K, Xu X, Fukao T, Canlas P, Maghirang-Rodriguez R, and others 2006. SublA is an ethylene-response-factor-like gene that confers submergence tolerance to rice. Nature 442:705-708.

Xu KN, Mackill DJ. 1996. A major locus for submergence tolerance mapped on rice chromosome 9. Mol Breed 2:219-224.

Young TE, Meeley RB, Gallie DR. 2004. ACC synthase expression regulates leaf performance and drought tolerance in maize. Plant J 40:813-825.

Zhang XL, Zhang ZJ, Chen J, Chen Q, Wang XC, and others 2005. Expressing TERF1 in tobacco enhances drought tolerance and abcisic acid sensitivity during seedling development. Planta 222:494-501.

Zhu JK. 2002. Salt and drought stress signal transduction in plants. Annu Rev Plant Biol 53:247-273. 